\title{
Tolerance Screening of Sugarcane Varieties Toward Waterlogging Stress
}

\author{
Sholeh Avivi $\left.{ }^{1,2, *}\right)$, Silvia Fitri Mei Arini ${ }^{1}$, Sigit Soeparjono ${ }^{1}$, Didik Pudji Restanto ${ }^{1,2}$, Wahyu Indra Duwi Fanata ${ }^{1,2}$, \\ and Ketut Anom Widjaya ${ }^{1}$ \\ ${ }^{1}$ Faculty of Agriculture, University of Jember, East Java, Indonesia \\ ${ }^{2}$ Center for Development Advance Sciences and Technology (CDAST), Jember University, East Java, \\ Indonesia
}

\begin{abstract}
The aim of this research was to obtain the resistant plant toward waterlogging stress. The research used complete randomized block design (RBD) with two factors and three replications. The first factors of sugarcane variety are PS 8845, VMC 7616, BL, VMC 86550, PSJK 922 and PS 864 . The second factor is the treatments of waterlogging on the level of treatment, that is, without waterlogging, 6, 9, and 12 weeks of waterlogging in bucket. The research results showed that the differences in resistance response of several tested varieties were seen in parameters of number of leaves, number of yellowing leaves, fresh weight of plant, plant height, stem diameter, root length, root's branch, number of tillers, chlorophyll content, the rate of photosynthesis, stomatal density, shoot leaf size, and leaf angle. Quantitative data character were analysed using ANOVA and DMRT. The conclusion of this research were that PS 8845 and VMC 7616 variety can be recommended as a variety that is resistant to water logging stress. While variety PSJK 922 showed the worst response in condition of waterlogging stress.
\end{abstract}

\section{INTRODUCTION}

Sugar has been used extensively for household and food industry [1]. Sugarcane household farm lands cultivate an area of 252.166 ha while private company sugarcane lands 198.131 ha.

Heavy rainfall in each region usually caused by extreme climatic change conditions, further impact of global warming [2]. Flooding is a common stress on agricultural land and the impact on plant growth by lowering the gas diffusion in the water [3]. The flooding can affect less well to the vegetative growth and grain yield of wheat [4].

One effort that can be made to the phenomenon of climate change and the occurrence of gaps fulfilment of sugar is to utilize marginal land such as waterlogged land for the expansion of sugarcane planting area. High tolerance to the flooding can improve plant's ability to survive in the environmental condition as opposed to the original [5]. Because it takes the availability of varieties that are resistant to the condition of agricultural land that often experience flooding. This research aims to determine the length of flooding that can be tolerated by sugarcane, identify sugarcane varieties that are resistant to flooding, and knowing the character of morphology and physiology of plants that are resistant to the flooding conditions.

\section{MATERIALS AND METHODS}

The materials consist of 6 selected sugarcane varieties PS 8845 (V1), VMC 7616 (V2), BL (V3), VMC 86550 (V4), PSJK 922 (V5), and PS 864 (V6). This research was done in vegetative phase of sugarcane in the age 4-7 month. The seedlings result from the single bud which developed in PG Prajekan, Indonesia. Sugarcane was planted in the polybag size $40 \mathrm{~cm} \times 45 \mathrm{~cm}$ [6]. The media composition was $1: 1: 1$ of land: sand: compost. ZA fertilizer for each plant was $14.4 \mathrm{~g}$. ZA was given twice that was in one week after planting, and one month after the first fertilizer application with the same dose [7]. Weeding is done 2 times and the water level is maintained at $10 \mathrm{~cm}$ below the soil surface for flooding treatment.

The experiment was arranged with the basic design of a randomized with three replications. Two treatment factors tested was sugarcane varieties (V) consisting of six varieties of sugarcane and the duration of flooding (L) with 4 levels of flooding time treatment: without flooding (P1), 6 week after planting/WAP (P2), 9 WAP (P3), and 12 WAP (P4). The Differences between treatments were tested by Duncan Multiple Range Test (DMRT) with a 95\% confidence level. The characters observed were the number of leaves, number of leaves turn yellow, fresh weight of leaf, stem fresh weight, plant height, stem diameter, root length, number of tillers, fresh weight of root, shoot leaf size, leaf angle and density of stomata. As for the quality of sugar is 
done by measuring the sucrose content of sugarcane. High sucrose sugarcane variety have $10 \%-15 \%$ of sucrose.

\section{RESULTS}

The sucrose content in each variety after tested by flood given in Figure 1. Every variety that tested to the duration of flooding has different response. Because of the higher of reducing sugar, must not for sugar crystallization process hence the lower the sucrose levels in cane sap, so the quality of the sap produced will also decrease.

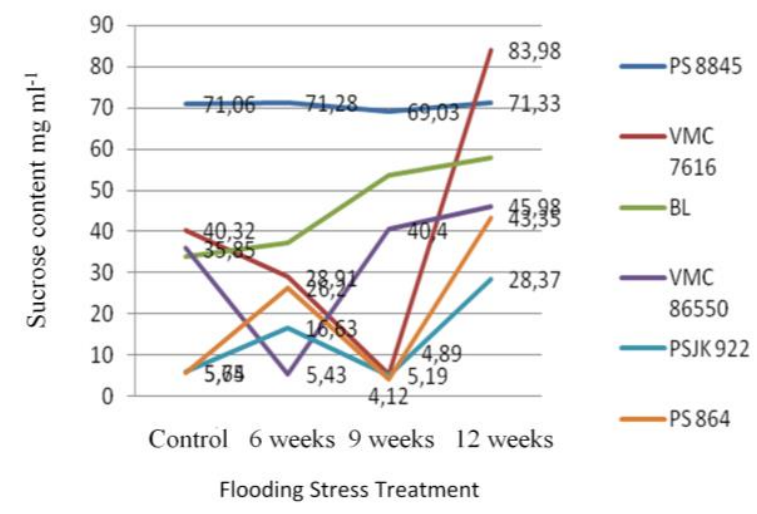

Figure 1. The sucrose content after flooding treatment

Based on the Figure 1, PS 864 variety has the lowest sucrose concentration of $4.12 \mathrm{mg} \mathrm{ml}-1$ at 9 weeks of flooding. However sucrose levels will increase along with the addition of treatment of 12 weeks of flooding. The same thing happened on the variety PSJK PS 864 and 922, which have the highest levels of sucrose in the 12-week flooding treatment compared with other treatments. VMC 86550 variety decreased sucrose levels at 6 weeks of flooding, while conditions in the initial flooding, at 9-12 weeks of flooding is likely to increase. For BL variety has high level of sucrose was increased along with the treatment of flooding. It means that the longer the treatment granting a puddle, then the sucrose content owned also higher (Figure 1).

PS 8845 varieties tend to be stable against flooding treatment. Since the beginning of the last flooding to flooding, these varieties tend to have a high content of sucrose fixed. So the sucrose content owned not affected by flooding treatment given. Varieties VMC 7616 decreased sucrose levels ranging from early flooding and flooding are likely to decline up to 9 weeks , but the pool of 12-week treatment increased sucrose levels were quite high $(83.98 \mathrm{mg} \mathrm{ml}-1)$. For the 12 -week treatment flooding, high sucrose content owned by VMC 7616.

Based on Figure 1, shows that the variety PS 8845 contains sucrose relatively stable against flooding treatment. For variety VMC 7616 has the highest content of sucrose in the provision of treatment of 12 weeks of flooding. Variety PS VMC 8845 and 7616 can be recommended for further investigation.

Table 1. Sugarcane sucrose level producted by flooding treatment.

\begin{tabular}{|c|c|c|c|c|}
\hline Varieties & $\begin{array}{c}\text { Flooding } \\
\text { treatment } \\
\text { (weeks) }\end{array}$ & $\begin{array}{l}\text { Sucrose } \\
\text { Content } \\
(\mathrm{mg} / \mathrm{ml})\end{array}$ & $\begin{array}{c}\text { Dry } \\
\text { weight } \\
\text { of Stem } \\
\text { (kg) }\end{array}$ & $\begin{array}{c}\text { Total } \\
\text { Sucr } \\
\text { ose } \\
(\%)\end{array}$ \\
\hline \multirow{4}{*}{ PS 8845} & 0 & 71,1 & 0,11 & 7,1 \\
\hline & 6 & 71,3 & 0,15 & 7,1 \\
\hline & 9 & 69,0 & 0,18 & 6,9 \\
\hline & 12 & 71,3 & 0,22 & 7,1 \\
\hline \multirow{4}{*}{$\begin{array}{l}\text { VMC } \\
7616\end{array}$} & 0 & 40,3 & 0,23 & 4,0 \\
\hline & 6 & 28,9 & 0,15 & 2,9 \\
\hline & 9 & 5,2 & 0,16 & 0,5 \\
\hline & 12 & 84,0 & 0,19 & 8,4 \\
\hline \multirow{4}{*}{$\mathrm{BL}$} & 0 & 33,9 & 0,12 & 3,4 \\
\hline & 6 & 37,4 & 0,31 & 3,7 \\
\hline & 9 & 53,5 & 0,47 & 5,4 \\
\hline & 12 & 57,8 & 0,42 & 5,8 \\
\hline \multirow{4}{*}{$\begin{array}{l}\text { VMC } \\
86550\end{array}$} & 0 & 35,9 & 0,16 & 3,4 \\
\hline & 6 & 5,4 & 0,25 & 0,5 \\
\hline & 9 & 40,4 & 0,34 & 4,0 \\
\hline & 12 & 46,0 & 0,42 & 4,6 \\
\hline \multirow{4}{*}{$\begin{array}{c}\text { PSJK } \\
922\end{array}$} & 0 & 5,8 & 0,25 & 0,6 \\
\hline & 6 & 16,6 & 0,33 & 1,7 \\
\hline & 9 & 4,9 & 0,28 & 0,5 \\
\hline & 12 & 28,4 & 0,52 & 2,8 \\
\hline \multirow{4}{*}{ PS 864} & 0 & 5,6 & 0,31 & 0,6 \\
\hline & 6 & 26,2 & 0,34 & 2,6 \\
\hline & 9 & 4,1 & 0,34 & 0,4 \\
\hline & 12 & 43,4 & 0,48 & 4,3 \\
\hline
\end{tabular}

The higher sucrose content is in variety $\mathrm{VMC}$ 7616 with treatment 12 weeks of flooding by $8,4 \%$ (Tabel 1). On this Combination treatment, obtainable highest sucrose content Namely $83.98 \mathrm{mg} \mathrm{ml}-1$, whereas for a review of the stem fresh weight $2.51 \mathrm{~kg}$. For sucrose lowest findings are varieties PS $864(0.4 \%)$ that were treated 9 weeks of flooding. Tabel 2 is a table that connects content of sucrose and sugar cane stem weight.

The formation of aerenchym stem (Figure 2) can be regarded as a form of stress adaptation of plants to stress flooding that occurred. Although formed aerenchym system, but note also contains sucrose contained therein. Based on sucrose content of the resulting table, it appears that the VMC 7616 variety was treated with 12 weeks of flooding have the highest content of sucrose. In addition to having the highest sucrose content, variety VMC 7616 is also able to form aerenchym in stems. So it can be said that this variety 
has the ability to adapt in planting conditions were flooded.

Table 2. Data of yellow leaves, fresh weight of stem, fresh weight of root, plant height, stem diameter, number of shoot, and stomata density after treatments.

\begin{tabular}{|c|c|c|c|c|c|}
\hline $\begin{array}{l}\text { Treat } \\
\text { ments }\end{array}$ & $\begin{array}{l}\text { Yello } \\
\text { w } \\
\text { Leaf }\end{array}$ & $\begin{array}{c}\text { Fresh } \\
\text { weight } \\
\text { of } \\
\text { Stem } \\
\text { (kg) }\end{array}$ & $\begin{array}{c}\text { Stem } \\
\text { Diamete } \\
\text { r } \\
(\mathrm{cm})\end{array}$ & $\begin{array}{l}\text { Number } \\
\text { of Shoot }\end{array}$ & $\begin{array}{c}\text { Stomata } \\
\text { Density } \\
\left(\mathbf{m m}^{-2}\right)\end{array}$ \\
\hline VIP1 & $4 j$ & $1,6 \mathrm{~h}$ & $1,6 \mathrm{ghi}$ & $7,3 \mathrm{a}$ & $32,1 \mathrm{~h}$ \\
\hline V2P1 & $4,3 \mathrm{ij}$ & $1,5 \mathrm{hi}$ & $2,3 \mathrm{bcd}$ & $6 \mathrm{bcd}$ & 41,4 fgh \\
\hline V3P1 & $3,3 \mathrm{j}$ & $1,5 \mathrm{hij}$ & $1,8 \mathrm{fgh}$ & $6,3 \mathrm{bc}$ & $38,4 \mathrm{gh}$ \\
\hline V4P1 & $5,3 \mathrm{ij}$ & $1 \mathrm{k}$ & $1,5 \mathrm{hi}$ & $6 \mathrm{bcd}$ & $31,1 \mathrm{~h}$ \\
\hline V5P1 & $3,3 \mathrm{j}$ & $1,1 \mathrm{ijk}$ & $2,1 \mathrm{def}$ & $6 \mathrm{bcd}$ & $31,1 \mathrm{~h}$ \\
\hline V6P1 & $3,6 \mathrm{j}$ & $1 \mathrm{k}$ & $2,5 \mathrm{~b}$ & 5,7 bcde & $35,2 \mathrm{gh}$ \\
\hline VIP2 & $\begin{array}{l}15,6 \\
\text { fghi }\end{array}$ & $1,7 \mathrm{gh}$ & $1,4 \mathrm{i}$ & $\begin{array}{c}4,7 \\
\text { cdefgh }\end{array}$ & $40,4 \mathrm{fgh}$ \\
\hline $\mathrm{V} 2 \mathrm{P} 2$ & $\begin{array}{c}12,6 \\
\text { ghi }\end{array}$ & $1,7 \mathrm{gh}$ & 1,8 fgh & 4 efgh & $42,5 \mathrm{fgh}$ \\
\hline V3P2 & $9 \mathrm{ij}$ & $\begin{array}{l}2,1 \\
\text { defg }\end{array}$ & 1,6 ghi & $6,7 \mathrm{~b}$ & 59,1 cde \\
\hline V4P2 & 21,6 ef & $1,1 \mathrm{jk}$ & $2 \mathrm{ef}$ & 5,3 bcdef & $57 \mathrm{cde}$ \\
\hline V5P2 & 9,6 hij & $1,9 \mathrm{fgh}$ & 2,2 cde & 5,6 bcde & $40,4 \mathrm{fgh}$ \\
\hline V6P2 & $18,3 \mathrm{fg}$ & $1,8 \mathrm{gh}$ & $1,8 \mathrm{fgh}$ & $6,3 \mathrm{bc}$ & $41,5 \mathrm{fgh}$ \\
\hline VIP3 & $29 \mathrm{de}$ & 2,3 cde & $3 a$ & $6,3 \mathrm{bc}$ & $65,3 \mathrm{bc}$ \\
\hline V2P3 & 22,6 ef & 2,3 cde & $2 \mathrm{ef}$ & $6 \mathrm{cbd}$ & 46,7 efg \\
\hline V3P3 & $18 \mathrm{fgh}$ & $2,5 \mathrm{c}$ & $1,8 \mathrm{fgh}$ & $6,7 \mathrm{~b}$ & 58,1 cde \\
\hline V4P3 & $36,3 \mathrm{~d}$ & 2,4 cde & $1,6 \mathrm{ghi}$ & $6 \mathrm{bcd}$ & $69,4 \mathrm{~b}$ \\
\hline V5P3 & $30 \mathrm{de}$ & $\begin{array}{l}2,2 \\
\text { cdef }\end{array}$ & 2,2 cde & 5 cdefg & 51,9 cdef \\
\hline V6P3 & $50 \mathrm{c}$ & $2 \mathrm{efg}$ & $1,8 \mathrm{fgh}$ & 5 cdefg & 59,1 cde \\
\hline VIP4 & $52 \mathrm{c}$ & $\begin{array}{l}2,3 \\
\text { cdef }\end{array}$ & $1,8 \mathrm{fgh}$ & $3 \mathrm{~h}$ & $63,2 \mathrm{bcd}$ \\
\hline $\mathrm{V} 2 \mathrm{P} 4$ & $32,6 \mathrm{~d}$ & $2,5 \mathrm{c}$ & $2 \mathrm{ef}$ & $3,3 \mathrm{gh}$ & $73,6 \mathrm{a}$ \\
\hline V3P4 & $35,3 \mathrm{~d}$ & $3,6 \mathrm{~b}$ & $2 \mathrm{ef}$ & $6,3 \mathrm{bc}$ & 67,4 bc \\
\hline V4P4 & $60,3 \mathrm{~b}$ & $2,5 \mathrm{~cd}$ & $2,1 \mathrm{def}$ & $6,3 \mathrm{bc}$ & $70,5 \mathrm{~b}$ \\
\hline V5P4 & $67,3 \mathrm{a}$ & $3,7 \mathrm{a}$ & $2,4 \mathrm{bc}$ & $6 \mathrm{bcd}$ & $59,1 \mathrm{cde}$ \\
\hline V6P4 & $54 \mathrm{bc}$ & $3,3 \mathrm{~b}$ & $1,9 \mathrm{fg}$ & 4,3 defgh & $65,3 \mathrm{bc}$ \\
\hline
\end{tabular}

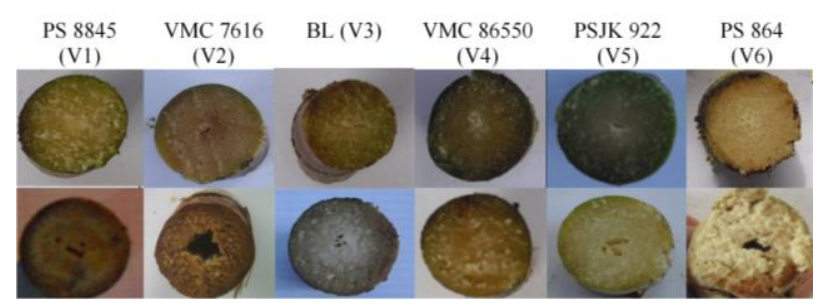

Figure 2. Cross-section of stem. Without flooding (upper), 12 weeks after flooding treatment (lower).
Table 2 shows that using variety takes a fact effect to the number of yellowing leaves, it visible on flooding 12 weeks of variety PSJK 922 has the highest number of yellowing leaves than other variety. While variety VMC 7616 has the lowest number of yellowing leaves than other variety. The value of the number of leaf yellowing negatively correlated with resistance properties of plants, where the higher is the number of leaf yellowing on treatment, then the plant resistance on stress flooding is reduced. On the contrary if the plant shows little of the number of yellowing leaves, then the resistance of that plant on stress flooding is higher. Therefore variety VMC 7616 has high resistance enough when treated puddle.

The existence of the value of the amount of yellowing leaves can be used as an indicator that a plant has resistance to flooding or not. Otherwise the value of the highest number of leaves turn yellow at 12 weeks of flooding seen in PSJK 922 variety, it can be presumed that this variety is not resistant to flooding conditions (poorly drained). Visual appearance leaves of sugarcane crops were experiencing flooding prone to chlorosis (yellowing leaves) and dried. One adaptation of crops to flooding stress characterized by the formation of aerenchym system, the Figure 2 is a cross-section of stem.

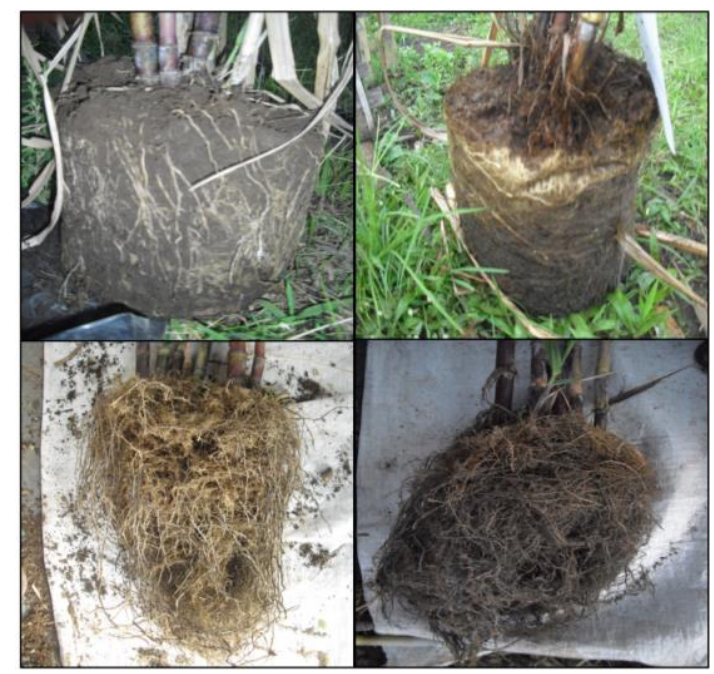

Figure 3. The sugar cane roots appearance variety VMC 7616 without flooding (left) and flooding sugar cane roots 12 weeks (right).

Highly significant effect on the treatment of long puddle on sugarcane root fresh weight after 12 weeks of treatment. Seen at PS 864 variety has the highest root fresh weight compared with other varieties. While the fresh weight of roots lowest for the PS 8845 variety. A responses variety of this variety is believed to be related to the ability of a plant to be able to adapt to the state of waterlogged soil conditions. In general the plants will form a new adventitious root as an adaptive response to the growing flooded environment. The treatments were given flooding has roots fresh weight value higher when compared to the fresh weight of the roots without puddles, this can be caused by adventitious roots growth more so add fresh weight of the roots of sugar cane. 
Visually the formation of adventitious roots in sugarcane shown by the Figure 3.

Figure 3 shows the appearance difference between root without flooding (left side) and root with flooding (right side). On the sugar cane which treated by flooding, forms many adventive roots, the tip of roots being black and decay, the rooting conditions more tightly and voluminous than control. This condition disturbing the absorption of nutrients.

Tabel 2, broadcaster varieties very significant effect on plant height parameter. Variety VMC 7616 has high value low crop if compared with other variety. The duration of flooding takes seriously effect to the high plant.

The result of analysis of variance (Table 2), variety is very significant effect on the number of tillers. In the treatment of 12 weeks of flooding, the highest number of tillers present in BL variety and VMC 86550. As for the lowest number of tillers present in sugarcane variety 8845 . Sugarcane productivity per unit of land is determined by the ability of the plant to form a seedling. The more puppies cane is formed, then the result will be more abundant sugar cane. Sugarcane saplings formed around the main stem. The main stem and tillers is what will serve as sugarcane milled [8].

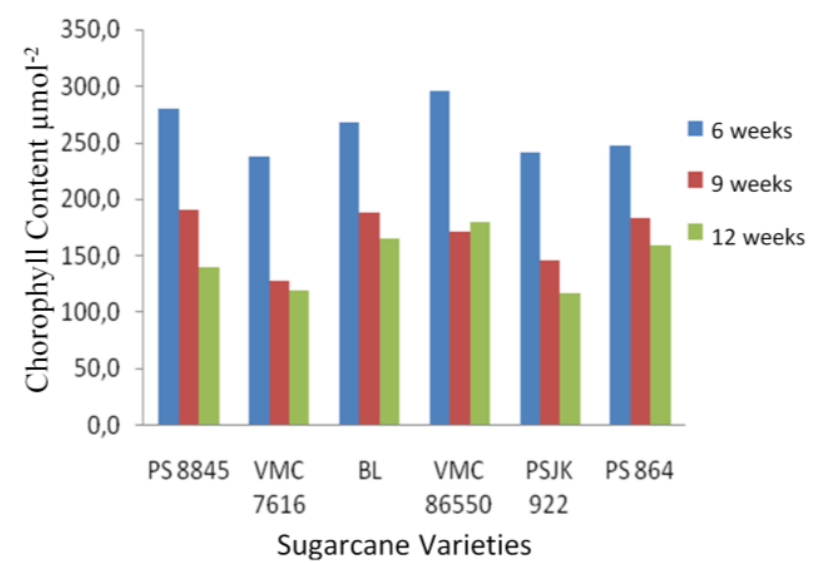

Figure 5. Chlorophyll content when flooding treatment at tested variety.

At 6 weeks of flooding treatment (Figure 5), the plants are still adapting to flooding stress given. So it looks that the chlorophyll content still fluctuated at 6 weeks of treatment flooding. Of all the varieties tested VMC 86550 and BL variety tends to decrease stress chlorophyll in 6 weeks. At 9 weeks of flooding treatment (Figure 5), variety decreased chlorophyll content more when compared with the flooding of 6 weeks. Treatment 9 weeks of flooding tends to decrease chlorophyll content in variety PS 8845 , VMC 86550 , PSJK 922, and VMC 7616. For 12 weeks of flooding, all varieties tested decreased chlorophyll content (Figure 5). From the figure above can be explained that the plants are experiencing flooding, all will experience a decrease in chlorophyll content.

This could be caused by granting the longer flooding stress, will cause leaf chlorosis experiencing more and more, so that the number of chlorophyll will be less. The leaves of the plant are flooded due to the rotting of the root system and destroyed. The process is the plant becomes unable to supply water and nutrients, especially $\mathrm{N}$, so that the need for water and $\mathrm{N}$ is not consummated as a result the leaves wither and eventually undergo yellowing or chlorosis [9].

\section{DISCUSSION}

Some plant responses are different even in terms of morphology, or to water stress. Besides morphology and physiology character, this trial looks to the sugar cane's quality (the sucrose content) which are contained in cane variety that given a flooding treatment.

A sugar cane is plant $\mathrm{C} 4$ and takes an important role in sugar industry (sucrose). Increased concentration of sucrose in the stem is the key of cane development program [10]. The ability of the sugar cane plant in accumulates sucrose determined by the activity of biosynthesis and degradation of sucrose. In sugarcane stem, internode is a place to accumulate sucrose. Sucrose is synthesized in the leaves of sugarcane translocated to the tissue/organ storage (stem) through the process of loading and unloading mechanism. In the sucrose stem will undergo further metabolism is hydrolysis. In the stems of young internode amount of energy and carbon framework is needed in large quantities, so the amount of sucrose hydrolysed also the greater the resulting sucrose content of the stem into small [11].

As described earlier, that the presence of reducing sugar is not needed to process of sugar crystallization. Then the value of the high sugar content reduction is not expected to exist. Here are the results of the measurement of reducing sugar in sugarcane after being given various treatments puddle. The higher the flooding that occurred during the active growth phase will affect the stem weight and yield [12]. The ability of plants to survive a response after receiving treatment plants flooding [9].

After experiencing flooding roots, and then leaves open to reduce the rate of transpiration and water loss and decrease the assimilation of photosynthesis as a result of the low capacity of photosynthesis and the leaf chlorosis experience. The change of colour of the leaves become yellow due to the flooding reduce the rate of photosynthesis in the initial flooding [13]. This stress flooding is the greatest environmental threat to plants. [14].

Excess water during flooding or flooding longer (generally called flooding) affects the growth of plants, the plant's ability to survive and distribution of species in the ecosystem [15]. Puddles resulted in a decrease in leaf area, the rate of plant growth, root growth and root hairs, stability index of the membrane, the rate of photosynthesis, chlorophyll and carotenoid content, rate of flowering, setting pods, yield and dry matter [16]. Puddle's water and soaking the plant is the main obstacle in the wetlands that impact on physiological processes and plant productivity [17].

On the crop which was experiencing flooding prone to chlorosis as like dcrease $\mathrm{N}$ phenomenon. $\mathrm{N}$ 
decrease due to decreased availability of $\mathrm{N}$ as well as a decrease in absorption. In the flooded availability of $\mathrm{N}$ in the form of nitrate is very low due to denitrification process that nitrate is converted into $\mathrm{N} 2, \mathrm{NO}, \mathrm{N} 2 \mathrm{O}$ or evaporate into the air [18].

The leaves on plants that were flooded on the third day will undergo withering. The morphology of leaves wilted due to root rot and crumble. The process is the roots are unable to absorb water and nutrients, especially $\mathrm{N}$, so that the water needs and $\mathrm{N}$ crown is insufficient as a result leaves wilted and yellow. In physiology, the leaves wither indicate the inability of plants to compensate for the transpiration process. Lack of water in the body of plants caused by lack of oxygen in the root zone [9].

At inundated crops, root absorption of water will perform on a large scale because of the presence of excess water in the root zone during flooded. So that more water is absorbed by the plant, then the plant must also be able to remove it from the body of the plant in order to be able to make the temperature inside the body to remain stable. So that there will be many stomata which aims to remove excess water from the body of the plant. Stomata density can affect two important processes in plants, namely photosynthesis and transpiration [19]. It can be concluded that the longer the flooding treatment can also increase the density of stomata in sugarcane [7].

Stomata conductivity fluctuated in giving treatment puddle, the highest during the flooding last long, where conditions are already experiencing chlorotic leaves and lowest CO2 assimilation [20]. Salinity and waterlogging are the two main factors that affect crop production around the world and often occur simultaneously, for example, salt is brought to the surface by rising water level [21]. Flooding or waterlogging is a major abiotic stress for plants [22].

The crop that capable to adapt in flooding condition will form aerenchym [23]. Losses due to flooding at the plant related to several factors such as the depth of flooding, long flooding and water flow during flooding [6]. Whatever forms the flooding also affects the physiology of sugarcane and cause uncertainty in production. Glaz et al. [24] said that there is a positive response from the characteristics of gas exchange in plants that experienced flooding. Conversely, according to Hasan et al. [25] reported a significant reduction in the growth of sugar cane stem on the condition of anoxia.

Chlorophyll is absorber solar radiation energy and as organelles able to convert radiant energy into chemical energy. Factors related to the plant, one of the physiological aspects that indirectly affect growth and yield of plants is chlorophyll. Chlorophyll is a plant internal factors that greatly affect the efficiency and the rate of photosynthesis. Plants that have high chlorophyll content will be very efficient in energy use sun radiation for carrying out the process of photosynthesis [26].

The root system of flooding plants is a type of spread, shorter and thicker but some amount less than the roots of other treatments; new roots have a thinner and slightly pink coloured by growing up as the previous explanation. Root crops have an important role in order to survive and remain productive even in waterlogged conditions [6]. Lack of oxygen shift from aerobic energy metabolism becomes anaerobic and therefore contributes less well to water absorption. As a result, the plant despite the lack of water available evens plenty of water [9].

Morphological characters of sugarcane that are resistant to flooding conditions, characterized by the formation of aerenchym in the roots, the emergence of adventitious roots, the plants tend to be a little percentage of deaths [24]. Additionally, the characters are experiencing stress physiology cane puddles are characterized by the rate of photosynthesis; chlorophyll and conductivity of stomata are likely to remain during the given flooding. As for the character of the plants that are not resistant inundated characterized by decreasing the rate of photosynthesis, chlorophyll and stomatal conductivity [6].

VMC 7616 variety is variety that is resistant to flooding. It seen of sucrose results generated for treated flooding. It appears that the VMC 7616 variety has the highest sucrose results $(8.398 \%)$ when compared to the others. Besides this variety also has the highest density of stomata $(73.61 \mathrm{~mm}-2)$. So despite the flooding were treated for 12 weeks, VMC 7616 variety tends to show the results of a high sucrose and high density of stomata. With the high density of stomata on the VMC 7616, so this variety tends to be adaptive to the waterlogged conditions. This is due to a growing number of stomata were formed, and then the excess water inside the plant body can be excluded as much as possible.

Based on the outcome of the experiment showed that PS 8845 as long as 12 weeks flooding stress had the stable highest sucrose levels by $71,3 \mathrm{mg} \mathrm{ml}-2$. While the lowest sucrose levels seen in varieties PS 864 with the sucrose stem content by $4.1 \mathrm{mg} \mathrm{ml}-2$. Varieties with the best response resistance to flooding stress was PS 8845, while varieties with the lowest response resistance indicated by varieties PS 864 .

\section{CONCLUSION}

Based on the outcome of the experiment showed that PS 8845 as long as 12 weeks flooding stress had the stable highest sucrose levels by $71,3 \mathrm{mg} \mathrm{ml}-2$. While the lowest sucrose levels seen in varieties PS 864 with the sucrose stem content by $4.1 \mathrm{mg} \mathrm{ml-2}$. Varieties with the best response resistance to flooding stress was PS 8845, while varieties with the lowest response resistance indicated by varieties PS 864 .

\section{ACKNOWLEDGMENT}

This research was supported by grant from the Directorate General of Higher Education Indonesia (contract no 273/UN25.3.1/LT/2015). 


\section{REFERENCES}

1. Sugiyanto, C. Jurnal Ekonomi Pembangunan. 8(2): $113-127$ (2010).

2. S.W. Lo, J.H. Wu, F.P. Lin, C.H. Hsu. Sensors 15: 2369-2387; (2015).

3. T. Dawood, I. Rieu, M.W. Arts, E.B. Derksen, M. Mariani, E.J.W. Visser. AoB PLANTS: plt058 doi: 10.1093/ aobpla/plt058. (2014).

4. L. Ercoli, A. Masoni, S. Pampana, M. Mariotti, I. Arduini. The Scientific World Journal. Vol. 2014, Article ID 717562, (2014).

5. Y. Chen, Y. Zhou, T.F. Yen, C.X. Liu, F.L. Luo. PLoS One. 8(11):e81456.doi: (2013).

6. H. Tedsushi, M.A. Karim. South Pacific Studies 28(1):9-22. (2007).

7. W.B. Widyasari, Damanhuri, H. Budhisantosa. MPG 47(1):10-27 (2011).

8. H. Rokhman, Taryono, Supriyanta. Vegetalika 3(3): 89 - 96. (2014).

9. Susilawati, R.A. Suwignyo, Munandar, M. Hasmeda, J. Agron. Indonesia 40 (3): 196-203. (2012).

10.H. Novita, Sumadi, D.P. Restanto, T.A. Siswoyo, B. Sugiharto. Jurnal Ilmu Dasar 8(2):118-127. (2007).

11. Miswar, B. Sugiharto., T. Handoyo, dan Made S.A. Agritrop 26(4):187-193. (2007).

12. M. K., Begum, Alam, M. R., \& Islam, M. S. (2013). World Journal of Agricultural Sciences 1 (2): 56-64.

13. R.T. Hapsari, M.M. Edie. Jurnal Litbang Pertanian 29(2):50-57. (2010).

14.C. Pucciariello, L.A.J. Voesenek, P. Perata, R. Sasidharan. Front Plant Sci. 5:226. (2014).

15.L.A.C.J. Voesenek, H.V. Veen, R., Sashidaran. AoB Plants. 6 (2014).

16.P., Kumar, M. Pal, R. Joshi, R.K. Sairam. Physiol Mol Biol Plants 19(2): 209-220. (2013).

17.B. Duarte, D. Santos, H. Silva, J.C. Marques, I. Caçador, N. Sleimi. AoB PLANTS 6: plu067; doi:10.1093/aobpla/plu067. (2014).

18. K. Hamonts, T.J. Clough, A. Stewart, P.W. Clinton, A.E. Richardson, S.A. Wakelin, M. O'Callaghan, L.M. Condron. FEMS Microbiol Ecol. 83(3):568-84. (2013).

19. E.G. Lestari, Biodiversitas 7(1):44-48. (2006).

20.P. Parolin, C. Lucas, M. Teresa, F. Wittmann. Annals of Botani 105: 129-139. (2010).

21.F. Zeng, Shabala, 1., Zhou, m., Zhang, G., and Shabala, S. Front Plant Sci. 4:313. (2013).

22. Y. Mano, Y. Takeda. Breed Sci. 62(1): 3-10. (2012).

23. K. Watanabe, S. Nishiuchi, K. Kulichikhin, M. Nakazono. Front Plant Sci. 4:178. (2013).

24.B. Glaz, D.R Morris, S.H Daroub. Crop Sci. 44:1633-1641. (2004).

25. M.F. Hasan, M.R. Alam, M.K. Begum, M.A.S. Miah. Pak. J.Biol. Sci. 6:1151-1155. (2004).

26. Safrizal, E. Santosa, Bakhtiar. J.Floratek, 3:61-67 (2008). 